\title{
Representaciones sociales sobre la migración de cubanos hacia Angola'
}

\author{
Social representations of Cuban migration to Angola
}

Yulianela Pérez García

\begin{abstract}
Resumen. Se analizan las representaciones sociales existentes en la migración de cubanos hacia Angola, así como su intervención en el proceso migratorio hacia ese destino. De manera que se explican las características del contexto histórico en que se construyen, se revisan sus principales contenidos desde la perspectiva de los migrantes y de las familias en el país de origen, además se examinan los elementos que intervienen en su construcción y la forma en que participan en la reproducción del proceso migratorio a través de las cadenas migratorias. Las representaciones sociales construidas desde Cuba sobre Angola, como destino potencial dirigido al cumplimiento de metas y aspiraciones de los migrantes, se hallan profundamente mediadas por el contexto de limitaciones del mercado laboral cubano. Así, los beneficios del proyecto migratorio se sobrevaloran como estrategia a fin de compensar esa situación en el nivel familiar. La imagen de «éxito» asociada a dicha migración de carácter laboral que circula por medio de cadenas migratorias influye en la reproducción del proceso migratorio.
\end{abstract}

Palabras clave. representaciones sociales, migración laboral, cadenas migratorias, contenidos de las representaciones sociales.

\begin{abstract}
This article presents an analysis of the existing social perceptions of Cuban migration to Angola, as well as their contribution to that migratory process. To that end, the historical context in which those perceptions are formed is characterized, including their key characteristics from the point of view of both migrants and families in the country of origin, as well as elements that affect their construction and the manner in which they influence the reproduction of the migratory process through migratory linkages. The social perceptions constructed in Cuba regarding Angola, as a potential destination where migrants might fulfill their goals and aspirations, are deeply integrated in the context of Cuba's limited labor market. Thus, the beneficiaries of the migratory process over-value it as a compensation strategy at the family level. The image of "success» associated with this migration in terms of labor that circulates through migratory ties influence the reproduction of this migratory process.
\end{abstract}

Keywords. social perceptions, labor migration, migratory ties, content of social perceptions.

${ }^{1}$ El artículo profundiza un tema esbozado parcialmente en el informe de investigación «Migración y trabajo entre las regiones del Sur desde la perspectiva global. Un análisis del flujo de cubanos hacia Angola», elaborado entre 2014-2015 y que resultó ganador del Concurso de Becas Sur-Sur 2014 «Trabajo y bienestar en el sur», organizado por el Programa de Colaboración Tricontinental Sur-Sur 2013-2015 entre el Consejo Latinoamericano de Ciencias Sociales (Clacso), el Consejo para el Desarrollo de las Ciencias Sociales en África (Codesria, por sus siglas en inglés) y la Asociación Internacional de Economía del Desarrollo (Ideas, por sus siglas en inglés). El informe fue publicado en 2015 y está disponible en la Librería Latinoamericana y Caribeña de Ciencias Sociales de Clacso, también puede consultarse en el siguiente enlace: http://www.clacso.org.ar/libreria-latinoamericana/libro_detalle.php?.orden $=\& i d \_l i b r o=10618$ pageNum_rs_libros $=0$ \&totalRows_rs_libros $=1027$ 



\section{Introducción}

El propósito de investigar el contexto y los elementos que forman parte de la construcción de las representaciones sociales concernientes a la migración de cubanos hacia Angola y cómo participan en el proceso migratorio no es propia, surgió de los estudios realizados por Gabriela Montero (2006) y Claudia Pedone (2002), quienes profundizan en las representaciones sociales de los emigrantes ecuatorianos en España.

Se analizan los elementos que intervienen en la conformación de las representaciones sociales sobre el proceso migratorio de cubanos hacia Angola y sus contenidos positivos o negativos. De igual modo, se determina la manera en que las construcciones apoyan el proceso migratorio al permitir su reproducción y continuidad, pese a los riesgos que presupone la migración hacia un destino no tradicional, muy distante de Cuba, donde el número de cubanos establecidos no es significativo en comparación con el total de cubanos emigrados y con las dificultades intrínsecas de un país con un Índice de Desarrollo Humano muy inferior, el cual se reconstruye tras largos años de conflicto bélico.

La migración externa de cubanos mostró un ligero incremento desde los 1990, debido sobre todo a la crítica situación socioeconómica que experimentó el país a consecuencia de su inserción en el mercado global en condiciones de franca desigualdad y por el bloqueo económico extendido casi por medio siglo. Uno de los reflejos del proceso de deterioro estructural se materializó en los insuficientes ingresos de la fuerza laboral cubana relativamente capacitada y en su limitado acceso al consumo y la movilidad social. Tales elementos incidieron en el aumento de los flujos migratorios externos como estrategia para «compensar» en el nivel micro los efectos estructurales de las erráticas políticas económicas. Así, la migración laboral se convirtió en una estrategia cada vez más recurrente.

Paralelamente, Angola destacó como nuevo destino de la migración laboral cubana en regiones que hasta entonces no eran receptores tradicionales. Las motivaciones de la migración hacia ese destino se vinculan con las características del mercado laboral cubano y los bajos ingresos, en comparación con las oportunidades que ofrece el país receptor y las posibilidades de recibir mayores beneficios. A partir de la inserción de estas personas en un nuevo mercado laboral que les permite obtener más ingresos, se han tejido nuevas relaciones que 
influyen en la construcción de una representación social positiva y exitosa. Así, la reproducción de las representaciones a través de las cadenas migratorias alienta la continuidad de la migración laboral hacia ese destino de forma paralela (trabajar por algunos años y luego regresar a Cuba) o definitiva.

Cabe mencionar que la migración laboral se refiere a la estrategia usada por aquellos que migran con el propósito de laborar por un salario con la finalidad de enviar remesas a sus hogares y, de ese modo, contribuir a mejorar las condiciones socioeconómicas de vida (personales y familiares), ante la imposibilidad de encontrar un empleo con una remuneración superior en su país de origen.

El estudio de las representaciones sociales en torno a la migración hacia Angola aportó significativos resultados, posterior a la aproximación crítica efectuada a las condicionantes que motivan y moldean el proceso migratorio cubano durante las últimas décadas, aunado a los flujos dirigidos hacia los destinos no tradicionales (países africanos). El análisis del contexto histórico de construcción y los elementos que intervienen en ese proceso contribuyó a profundizar en la dinámica actual y el comportamiento de la migración cubana, en específico la de carácter laboral. Complementariamente, se aportaron elementos que refuerzan la pertinencia de modificar la tradicional connotación política e ideológica otorgada al aspecto migratorio desde 1959 en cualquier espacio de la sociedad cubana.

La consecución de los objetivos implicó el uso de técnicas procedentes de la metodología cualitativa, entre ellas las entrevistas en profundidad, las cuales posibilitaron interpretar las experiencias migratorias de los cubanos establecidos en Angola y la de los familiares de migrantes en la Isla. En total se llevaron a cabo veinte entrevistas: diez dirigidas a familiares de migrantes cubanos asentados en Angola y diez dirigidas a cubanos que trabajan en este destino. Las personas seleccionadas respondieron a criterios de selectividad cualitativa: sexo, antigüedad de la migración, nivel educativo, profesión y ocupación en Angola. El trabajo de campo se realizó en la provincia de La Habana, Cuba, entre los meses de enero a junio de 2015. Todas las familias de los migrantes radican en dicha provincia. Los migrantes asentados en Luanda fueron entrevistados durante sus vacaciones en la isla.

Los resultados se articularon en tres aspectos fundamentales: en el primero se explican las características del contexto histórico en que se construyen las representaciones sociales, en el segundo se revisan los principales contenidos de esas representaciones desde la perspectiva de los migrantes y de las familias en 
el país de origen, en el tercero se examinan los elementos que intervienen en la construcción de las representaciones y cómo participan en el proceso mediante la función de las cadenas migratorias.

Antes de continuar es imprescindible esclarecer los marcos conceptuales que orientaron este estudio y que se asocian con dos categorías esenciales: representaciones sociales y cadenas migratorias. Existe un consenso en definir a las representaciones sociales como una interpretación idealizada de determinado proceso social, construidas por individuos que interactúan en contextos sociales particulares. Asimismo, constituyen formas del conocimiento práctico orientadas hacia la comunicación y la comprensión del entorno social, que facilitan el proceso de orientación y decisión de los sujetos (Jodelet, 1984:474). No obstante, este amplio concepto, que denota la complejidad intrínseca del fenómeno, ha sido indistintamente empleado por múltiples autores según los intereses de sus estudios.

La aproximación teórica más importante es la que plantea Serge Moscovici: "La representación social es una modalidad particular del conocimiento, cuya función es la elaboración de los conocimientos y la comunicación entre los individuos» (1979:17). Denise Jodelet, Robert Farr, María A. Banchs, Di Giacomo y Dario Páez, entre otros, han dado continuidad a la obra de Moscovici y han elaborado contribuciones teóricas e investigaciones empíricas en distintas direcciones y enfoques (Araya, 2002 y Mora, 2002). Por su parte, Montero define las representaciones asociadas al proceso migratorio como práctica social de la siguiente manera:

Las representaciones sociales que se construyen sobre la migración pertenecen a una realidad concreta que se inserta dentro de un contexto a partir de las experiencias y vivencias de un grupo sociocultural, donde la presencia de elementos subjetivos — sentimientos, motivaciones, expectativas — influyen sobre sus comportamientos y en la toma de decisiones (Montero, 2006:38).

Las representaciones sociales referidas al proceso migratorio cubano hacia Angola se articulan como construcciones simbólicas que permiten a los actores involucrados clasificar y valorar el acto migratorio con fines laborales. Los puntos de referencia para la organización de dicho conocimiento social se estructuran a partir de la percepción que se tiene acerca de la realidad inmediata, en este caso el contexto social y económico cubano, incluso las dinámicas de movimiento del 
mercado laboral cubano contemporáneo y el reflejo de sus principales problemas en la fuerza laboral. Tal escenario constituye un elemento crucial en la representación positiva de un país que aunque posea un desarrollo humano inferior al cubano ofrece oportunidades de crecimiento que no se identifican en el contexto de origen. Respecto a la concepción de las metas y aspiraciones del proyecto migratorio, relacionadas con las necesidades insatisfechas en el ámbito cubano, la definición de «éxito» se asocia al cumplimiento de estas necesidades y a la valoración positiva sobre la migración laboral como estrategia para diversificar e incrementar los ingresos, y con ello el consumo y la movilidad social tanto de los migrantes como de sus familias en Cuba. Referente a la definición de cadenas migratorias, diversos autores establecen una diferenciación teóricometodológica entre cadenas y redes migratorias (Pedone, 2002 y 2010; Gaete y Rodríguez, 2010).

La cadena migratoria se refiere a la transferencia de información y apoyos materiales que familiares, amigos o paisanos ofrecen a los potenciales migrantes para decidir, o eventualmente, concretar su viaje. Las cadenas facilitan el proceso de salida y de llegada, pueden financiar en parte el viaje, gestionar documentación o empleo y conseguir vivienda. También en ellas se produce un intercambio de información sobre los aspectos económicos, sociales y políticos de la sociedad de llegada (...) Las cadenas forman parte de una estructura mayor: las redes migratorias (Pedone, 2010:107).

De acuerdo con las características del objeto de estudio de esta investigación, se asume la categoría de cadenas migratorias, restringidas a la unidad familiar y grupo de amigos. Si bien pueden alcanzar dimensiones transnacionales por la propia dinámica del proceso migratorio, son vínculos informales y reducidos al grupo de personas conectadas con los migrantes.

Las cadenas migratorias son, por tanto, un subconjunto particular de redes migratorias que vinculan a migrantes, antiguos migrantes y potenciales migrantes o no migrantes en un proceso de un intercambio de información y soporte que reduce sustancialmente la incertidumbre y los costos afectivos y materiales del traslado y que facilita, en un primer momento, la inserción del emigrante en la sociedad de destino, siendo por ello especialmente explicativas de las decisiones de emigrar (Gaete y Rodríguez, 2010:700). 


\section{Contexto histórico}

Desde la década de 1990 y principalmente en los albores del siglo XXI, África y Asia se han configurado como nuevos destinos de la migración externa de cubanos (Sorolla, 2013). En este contexto, Angola constituye el principal centro de recepción de cubanos y de los flujos inter y extra continentales, a partir de 2002 cuando inicia un periodo de cierta estabilidad política luego de la firma de los acuerdos de alto al fuego y la proclamación del fin de la guerra civil que se había extendido por más de 25 años. Desde entonces, son múltiples las fuentes que indican el constante incremento del número de extranjeros en el país y la creciente incidencia de expulsiones de inmigrantes en situación irregular (Baldé, 2012; ANGOP, 2014).

Con base en las fuentes consultadas, las causas fundamentales tras este proceso son el rápido crecimiento de la economía angolana y las oportunidades de trabajo que se ofrecen. El Fondo Monetario Internacional (FMI) estimó que la tasa de crecimiento de su producto interno bruto (PIB) entre el año 2002 y 2011 había sido de 11.6 por ciento, superior a la de China, Nigeria, India, Rusia, Brasil y Sudáfrica (Jover, Lopes y Marchand, 2012:8). Aunque las bases de ese acelerado crecimiento económico se encuentran en el incremento de la producción y exportación de petróleo, dicha industria ha estimulado el desarrollo de otros sectores (servicios financieros, construcción, manufactura y agricultura). Con todo y esto, la realidad social del país es completamente diferente a la dinámica del crecimiento económico. Según datos publicados por el Fondo de las Naciones Unidas para la Infancia (Unicef, por sus siglas en inglés) correspondientes al año 2014, la población del país tenía una esperanza de vida al nacer de 52 años, la tasa de mortalidad infantil fue de cien niños por cada mil nacidos vivos y la tasa de analfabetismo se calculó en 30 por ciento (Unicef, 2015).

Asimismo, es significativo que del total de la población asentada en centros urbanos, 51 por ciento no dispone de fuentes seguras de agua y 58 por ciento no cuenta con condiciones mínimas de sanidad (ICPD, 2012). Tales cifras son el resultado del proceso de sobrepoblación de los principales centros urbanos, ubicados generalmente en la zona costera, la cual recibió a muchos de los desplazados internos por la guerra y la desestructuración de las economías rurales debido a los modelos de explotación neoliberal. De acuerdo con datos del Censo Nacional publicados en octubre de 2014 por el Instituto Nacional de Estadística (INE), Luanda albergaba a 6.5 millones de habitantes, 27 por ciento del total de 
la población (INE, 2014:23). En condiciones de hacinamiento e insalubridad es común la persistencia de diversas enfermedades (tuberculosis, neumonía, paludismo, diarreas) que afectan mayormente a la población infantil.

Una de las dificultades más graves que enfrenta el país en la actualidad es la amplia brecha social en cuanto al nivel de ingresos de la población. El coeficiente de Gini se incrementó entre 1995 y 2000 de 0.45 a 0.51 (ONU, 2002), y en 2012 se calculaba en 0.58 (OID-MAEC, 2012). Varios elementos refuerzan esa tendencia: la desigual distribución de las riquezas nacionales, la corrupción extendida a todos los niveles de dirección y la lenta generación de empleos como requerimiento imprescindible para la reducción de la pobreza.

El esfuerzo general de reconstrucción nacional ha demandado la existencia de un recurso vital: suficiente mano de obra, calificada de preferencia, con la cual Angola no cuenta. Como alternativa, el Estado ha flexibilizado la inmigración de trabajadores, principalmente de individuos calificados, no sólo de origen africano sino también extracontinental, atrayéndolos con elevadas remuneraciones. Gracias a estas iniciativas, y pese a la compleja situación de los servicios sociales, han arribado a suelo angolano miles de extranjeros en busca de empleos con mejores remuneraciones que les permitan ahorrar fondos y enviar remesas a sus países de origen. ${ }^{2}$

Referente a la migración de cubanos, desde los 1970 se han registrado asentamientos aislados por uniones con conyugues angolanos que derivaron con la presencia militar o la colaboración civil cubana en la nación africana (Amaro, 2013). Sin embargo, el carácter de Angola como país receptor comienza a manifestarse después del año 2000, momento en que ocurre la mayoría de los asentamientos; en 2007, por ejemplo, se registraron mil 096 (López, 2008:15) y desde 2010 hasta 2013 el número de cubanos en Angola se mantuvo alrededor de los 2 mil individuos, considerando solamente las cifras referidas a los migrantes definitivos (Pérez, 2015:57; CEMI, 2014:10).

\footnotetext{
${ }^{2}$ En el informe de la Organización Internacional para las Migraciones (OIM) de 2013 se incluye el relato de un joven médico peruano que vive y trabaja en una clínica privada en Luanda desde 2010, quien declara: "Quiero permanecer en Luanda principalmente porque el trabajo conlleva una serie de responsabilidades importantes y el sueldo es mucho más elevado del que ganaría en el Perú realizando el mismo trabajo (...) Estar aquí me ha permitido alcanzar algunas metas muy positivas en términos de dinero y ahorros» (OIM, 2014:28-29).
} 
A partir de estudios previos sobre los cubanos establecidos en Angola, ${ }^{3}$ ya sea de manera temporal o definitiva, se ha constatado que no existen diferencias significativas entre este grupo de migrantes y el resto de la migración cubana internacional en cuanto a las características sociodemográficas esenciales como sexo, color de la piel y edad (Martín Fernández, Aja, Casaña y Martín Quijano, 2007). En este sentido, se observa una migración compuesta mayoritariamente por hombres de raza blanca y en edad laboral activa. ${ }^{4}$ Destaca el elevado número de personas calificadas que componen este grupo y el importante porcentaje de aquellos que han tenido un desarrollo profesional vinculado al área de la salud, personas que además continúan trabajando en Angola en ese sector. ${ }^{5}$ Se trata de una migración de carácter temporal, pues la mayoría de los encuestados declaró su deseo de regresar a Cuba luego de unos años, además se compone por individuos que viajan solos y que se sienten motivados por cuestiones económicas y laborales.

El incremento y la diversificación geográfica de los flujos migratorios externos de cubanos hacia estas regiones no tradicionales desde la década de 1990, se dilucida atendiendo a múltiples elementos, aunque los más significativos se asocian con factores socioeconómicos relacionados a su vez con el desarrollo histórico de Cuba. En los albores de 1990, la economía cubana experimentó una

${ }^{3}$ En el 2012 se realizó el primer estudio exploratorio sobre las características de los cubanos establecidos en Angola a partir de la aplicación de un cuestionario diseñado por el Centro de Estudios de Migraciones Internacionales (CEMI) de la Universidad de La Habana, a 67 cubanos emigrados, todos residentes en la ciudad de Luanda, capital del país, por mediación del Consulado de Cuba en Angola. Entre los meses de febrero y abril de 2015, este proceso se repitió y se logró encuestar a una muestra compuesta por 10 por ciento de los cubanos radicados en suelo angolano, cifra que no incluye a los colaboradores civiles que se encontraban prestando sus servicios en la nación. Los sujetos de la muestra se distribuyen entre hombres y mujeres desde los 24 hasta los 69 años de edad, todos radicados en diez provincias angolanas, de ellas Luanda es la más representativa al concentrar 90 por ciento de los casos. Para mayor información en cuanto al procesamiento y el análisis de los datos proporcionados por el cuestionario, véase Pérez, 2015:71-81.

${ }^{4}$ Según los resultados arrojados por el cuestionario los hombres representan 64 por ciento del total de la muestra, la piel blanca es la que predomina para hombres y mujeres (66 por ciento) y, acerca de la distribución de frecuencias de la edad de la muestra, la mayor concentración se expresa entre las edades de 31 a 60 años (Pérez, 2015:73-76).

${ }^{5}$ Con base en los resultados del cuestionario resalta que el nivel educacional terminado en Cuba predominante entre los emigrados es el de universitario (60 por ciento), de ellos 32 por ciento cursó estudios de posgrado. Del total de encuestados con nivel universitario o superior, los graduados de especialidades relacionadas con el área de la salud, como medicina general, enfermería, estomatología maxilofacial y anestesiología constituyen 41 por ciento. Por otra parte, 73 por ciento de los encuestados declaró trabajar en la esfera de la salud o la educación en Angola (Pérez, 2015:76-78). 
profunda crisis, ${ }^{6}$ cuyos detonantes principales fueron la acumulación de errores y deficiencias de ciclos productivos previos, el impacto negativo que produjo el derrumbe del bloque socialista en Europa Oriental, la reinserción del país en el sistema capitalista mundial en condiciones de intercambio desigual y el recrudecimiento del bloqueo económico impuesto por los Estados Unidos desde 1962 (Pérez, 2009).

Esta crisis económica y las decisiones tomadas para amortiguar sus efectos, se manifestaron de inmediato en el deterioro general de las condiciones de vida de la población cubana, ello desencadenó una serie de problemas: creciente carencia de recursos monetarios para adquirir bienes necesarios por parte de amplios sectores de la fuerza laboral, reducción del acceso a un grupo muy limitado de productos, exclusión de segmentos básicos de la población del consumo en el mercado de divisa extranjera, surgimiento de niveles de vida separados de los resultados del trabajo, aparición de una elite trabajadora y una reestratificación social (Togores, 2000:2; Espina, 2009:182-183).

Otra dimensión sobresaliente en la que incidió la crisis económica de principios de la década de 1990 fue en el sistema de relaciones sociales de trabajo. Sus consecuencias negativas, aún hoy sin solución, se reflejaron en las visibles diferencias en la calidad del empleo, las cuales no se corresponden con el desempeño, la cualificación o la importancia social de la actividad que lo justifica. En esa misma dirección se suma el aspecto del ineficaz sistema de gratificación por el trabajo, disociado por completo de los niveles reales de productividad. Pese al progresivo incremento del salario de los cubanos en términos nominales su valor real no se corresponde con las necesidades de consumo.7 Finalmente, la falta de coincidencias entre las demandas de los contenidos de trabajo y las competencias de quienes los asumen en términos de calificación y capacidad, quedan subutilizadas, al igual que las potencialidades de la fuerza laboral

${ }^{6}$ La magnitud y la rapidez del proceso de contracción económica que experimentó Cuba durante esos años se reflejó en el deterioro abrupto de importantes indicadores: reducción en 70 por ciento del intercambio comercial en 1992 con respecto a 1989, decrecimiento del PIB en 24 por ciento durante el mismo periodo, disminución del uso de la capacidad industrial instalada en 30 por ciento (Silva, 2003:123).

${ }^{7}$ De acuerdo con Vidal, Pérez Villanueva y González, en 2009 el salario promedio mensual en Cuba era de 429 pesos cubanos, lo que en términos nominales representaba un incremento de 51 por ciento respecto a 2004. Sin embargo, al tipo de cambio vigente en la Isla, de 25 pesos cubanos por peso convertible, el salario medio mensual equivalía a 17.16 pesos convertibles o 18.53 dólares estadounidenses, lo que hace que sea uno de los desafíos más serios para la economía cubana en la actualidad (Vidal, Pérez y González, 2010:6). 
caracterizadas además por su calificación relativamente media-altå (Martín, 2012:37-41).

La acumulación de tales tensiones internas, agudizadas a partir de la crisis de 1990, condujo al aumento de los índices de la migración externa cubana (ONEI, 2014a:98). En opinión de Edel J. Fresneda Camacho, la migración externa, temporal y definitiva, se constituye como estrategia de "compensación de las distorsiones estructurales» que busca contrarrestar el reflejo de los efectos socioeconómicos de las distorsiones propias del sistema productivo cubano y de su inserción en el contexto internacional.

En este sentido, la migración internacional funge como elemento que parcialmente subsana tales distorsiones por medio de las remesas, que operan como ingresos familiares en el plano individual, y las divisas en la esfera macroeconómica que proporciona la fuerza de trabajo calificada al intentar mecanismos de movilidad alternos al mercado laboral cubano (Fresneda, 2014:120).

Las circunstancias del contexto interno cubano sustentan la diversificación de los destinos de la migración cubana y la incorporación de nuevos centros de recepción con niveles de desarrollo humano inferiores, como es el caso de Angola. ${ }^{9}$ La migración hacia dicho país como estrategia de "compensación» se halla impulsada en especial por razones económicas y de desarrollo laboral y profesional en el escenario de origen. La percepción comparativa de las diferencias salariales moviliza el proyecto migratorio, aun cuando se tienen garantizados servicios vitales (como la salud y la educación) con una calidad media relativa, situación muy diferente en lugar receptor. La expectativa de un mejor salario que se desdoble en bienes materiales para el emigrado, y beneficios financieros y materiales a través de las remesas para las familias en Cuba es un fuerte incentivo.

El incremento del saldo migratorio y la diversificación de los destinos de recepción se efectuaron en un periodo de cambios y flexibilización en la actitud social hacia la migración, no sólo por parte de las instituciones que controlan

${ }^{8}$ En 2013 se calculó que del total de la fuerza de trabajo cubana ocupada (4 millones 918 mil 800) 73.3 por ciento tenía nivel medio superior o superior (ONEI, 2014b:170).

9 Según el Informe sobre desarrollo humano de 2014, Angola ocupó el puesto número 149, lo que lo ubicó en el grupo de países con un desarrollo humano bajo; a diferencia de Cuba, situado en el número 44, dentro de los países con un índice muy alto (PNUD, 2014:176-178). 
su gestión y de aquellas que desde la academia la estudian, sino por la sociedad cubana en general. Estudios realizados a comienzos de los $2000^{10}$ demuestran que a partir de los 1990 han ocurrido cambios y modificaciones en la manera en que la sociedad concibe a la migración externa y en su connotación al interior de la sociedad cubana; tales cambios reflejan las condiciones del contexto histórico nacional de ese momento.

Otros elementos clave que contribuye a explicar la importancia de Angola como principal destino de la migración de cubanos hacia el continente africano son las relaciones que ha sostenido el gobierno cubano con ese país desde el triunfo de la revolución. Con el nuevo gobierno se catalizaron las relaciones políticas, económicas y culturales con las naciones africanas y asiáticas, las cuales han permitido el acercamiento entre sus pueblos. Angola, en particular, ha sido beneficiada por la política de solidaridad internacional cubana desde mediados de la década de 1960 (González, 2011; González y Lord, 2014). El apoyo del gobierno y del pueblo cubanos a la lucha del Movimiento Popular de Liberación de Angola (MPLA), la amplia presencia de personal cubano en la esfera militar y la colaboración civil en materia de salud, educación y desarrollo tecnológico, son algunas de las dimensiones de los vínculos que se han promovido entre ambas naciones. ${ }^{11}$ La política de solidaridad seguida por Cuba durante esos

${ }^{10}$ En el área de los estudios sobre la migración externa cubana, ya se habían llevado a cabo aproximaciones desde los primeros años del siglo XXI referentes a lo que se denominó «la evolución de la connotación social de la emigración en una perspectiva psicosocial histórica» (Martín Fernández, Aja, Casaña y Martín Quijano, 2007). Estos estudios, impulsados en su mayoría por Consuelo Martín Fernández, se concentraron en análisis derivados de entrevistas a individuos procedentes de la ciudad de La Habana y con vínculos o no con la emigración hacia Estados Unidos. En esa ocasión se les interrogó en cuanto a sus percepciones de la emigración en el país en periodos históricos concretos (19591979, 1980-1989, 1990-1999) que se establecieron a partir de la historia y las características de la emigración cubana.

${ }^{11}$ Desde el inicio de las operaciones de la Misión Militar Cubana (MMCA) en apoyo al MPLA y por solicitud y aprobación de Agostinho Neto, en 1975 y hasta 1991, cuando se retiraron las tropas cubanas, cerca de 430 mil cubanos sirvieron en misiones internacionalistas en el ámbito militar y en el programa de cooperación civil en el que participaron doctores, profesores, técnicos y trabajadores de la construcción (George, 2005:143). La prolongada presencia cubana constituyó el marco esencial para el establecimiento de vínculos sociales y culturales. De modo similar, en años recientes la continuidad de los programas de colaboración civil ha permitido la constante presencia de cubanos en Angola y viceversa. Al cierre del año 2014, varias fuentes periodísticas cubanas informaron que más de 4 mil colaboradores cubanos estaban prestando servicios en Angola, la gran mayoría en los sectores de salud y educación, el resto en actividades como construcción, cultura, energía y agua, combate a la malaria, entre otros. A la vez, como parte de la política de formación y capacitación de estudiantes angolanos en suelo cubano desde la década de 1970, fuentes oficiales cubanas apuntaban que a finales del mismo año más de 
años ha sido ampliamente reconocida por el gobierno y el pueblo angolanos y ha servido de trasfondo del nivel de aceptación y prestigio que tienen los cubanos, en especial los profesionales, en la sociedad angolana.

Por último, existen otros factores de carácter internacional que también contextualizan la migración de cubanos hacia Angola y participan en la construcción de sus representaciones sociales. Se relacionan con la naturaleza actual del escenario internacional en que se desarrolla la migración y explican su creciente tendencia al incremento y la diversificación de tipologías y destinos. En la reconfiguración del orden mundial actual, cuya base es la consolidación de las tendencias globalizadoras respaldadas por las concepciones neoliberales, la migración ha desempeñado una función central en la producción y acumulación de capitales y en la expansión geopolítica del sistema. Asimismo, el proceso de globalización neoliberal ha profundizado las condiciones estructurales de las que resulta la migración. En ese sentido, la conformación de un mercado global de trabajo altamente segmentado ha revalorizado la migración como mercancía en función de los capitales centrales: «La migración internacional se plantea como un mercado en el cual los trabajadores pueden decidir libremente trasladarse al área donde recibirán el ingreso más alto» (Castles, 2013:23).

En el escenario global posterior a la década de 1990, Cuba (con un modelo de producción impulsado por principios no capitalistas pero que se encuentra en una crisis sistémica desde décadas anteriores) ha ocupado una posición geopolítica periférica y desventajosa según sus bajos niveles de productividad y a la histórica dependencia de sistemas de intercambio internacionales de tipo preferencial. En las condiciones del subdesarrollo cubano, la fuerza laboral, generalmente con una capacitación media-alta y subutilizada en atención al crecimiento económico del país, se encuentra más vulnerable hoy que en los 1990 a los procesos de deterioro social y del trabajo como medio de satisfacción de sus necesidades, a la mayor diferenciación en los ingresos y el consumo, al fortalecimiento de situaciones de pobreza y de las brechas de equidad relacionadas con el género y la raza (pese a que las políticas sociales tienen una dimensión universal) y a la selectividad en el patrón de movilidad social (Espina, 2015:265-268).

Ante esa situación, es frecuente que un segmento de la fuerza laboral cubana identifique en mercados laborales externos las posibilidades de contar con 
un trabajo que le permita obtener mayores niveles de ingreso, consumo y movilidad social a partir de sus capacidades y potencialidades. En la actualidad, dichos mercados laborales han cobrado relevancia por la interconexión que propicia el rápido desarrollo tecnológico de los medios de comunicación y el transporte. El flujo de información entre los cubanos insertados en ellos y sus familiares y amigos en la Isla, también hace plausible acceder al conocimiento de las diferencias entre la situación del mundo del trabajo y las relaciones sociales en Cuba y más allá de sus fronteras.

Así, la construcción de las representaciones sociales concernientes a la migración de cubanos hacia Angola depende de varios factores. Los más inmediatos son las contradicciones estructurales que imponen limitaciones al desarrollo cubano en el presente y su reflejo negativo sobre la fuerza laboral cubana, el cual se combina con las probabilidades de crecimiento económico ofrecidas por Angola, que constituyen un atractivo en los planos local (nación) y micro (familiar e individual) y determinan su elección. El marco de las relaciones históricas entre Cuba y Angola conforma el antecedente de la migración contemporánea de cubanos, la cual se dirige hacia un país no tan desconocido y en el que los cubanos son considerados de modo positivo por su prestigio y profesionalidad. La tendencia hacia el crecimiento y la diversificación de la movilidad internacional evidencia un proceso más global y no exclusivo de la migración externa cubana.

\section{Revisión de los contenidos de las representaciones sociales: la perspectiva de los migrantes}

Con anterioridad se mencionó que a partir de los 1990 ocurre un cambio en la forma en que se representa socialmente la migración. Desde entonces, los estudios apuntan su mayor percepción como estrategia de enfrentamiento y solución en los ámbitos individual y familiar a la situación socioeconómica del país (Martín Fernández, Aja, Casaña y Martín Quijano, 2007; Fresneda y Delgado, 2013; Fresneda, 2014; Arboleya, 2013):

La representación social de emigrar se asocia a elementos directamente relacionados con las alternativas de «solución» a las situaciones generadas por la «crisis económica» que atraviesa el país. Esto significa un importante cambio de tendencia 
en los contenidos centrales que estructuran la representación social de emigrar; en el pensamiento cotidiano la dimensión clasista ha desaparecido y la dimensión político-ideológica se ha movido para abrir el espacio a un espectro mucho más matizado por lo económico y lo familiar y por tanto, menos politizado (Martín Fernández, Aja, Casaña y Martín Quijano, 2007:157).

Las representaciones sociales relativas a la migración de cubanos hacia Angola no escapan de ese proceso de cambios. Al tratarse de un flujo de carácter laboral, sus representaciones sociales reflejan las condiciones del contexto de origen como motivadores primordiales de la migración. No obstante, es necesario analizar con detenimiento sus contenidos y los lazos que guardan con la dinámica del proceso migratorio. Para este análisis, los contenidos se agruparon en cinco dimensiones fundamentales: 1) representaciones sobre los países de destino y de origen, 2) motivaciones y aspiraciones 3) definición de «éxito», 4) opinión sobre el proyecto migratorio, 5) regreso a Cuba. Las dimensiones se consideraron desde la perspectiva de los migrantes a partir de los testimonios recabados mediante las entrevistas en profundidad realizadas a los cubanos residentes en Angola, ya fuera de manera temporal o definitiva. Además, el estudio se complementó con la perspectiva ofrecida en las entrevistas por las personas residentes en Cuba que al menos contaban con un familiar en el país africano.

Representaciones sobre los países de destino y de origen

Adquiere significativa importancia en el proyecto migratorio la manera en que se representan los potenciales lugares de destino desde el lugar de origen, aspecto que se integra a las condicionantes de la decisión migratoria (Pedone, 2002:57). En esa dirección, Montero advierte que la dimensión cultural del proceso migratorio revaloriza su componente de «imitación de modelos impuestos», los que también influyen en el momento de la toma de decisión para iniciar el proyecto migratorio. Complementariamente explica que son varios los elementos que intervienen:

La poca difusión de los elementos culturales de los países subdesarrollados y la mayor difusión de las culturas que se han convertido en culturas dominantes, por el nivel de desarrollo alcanzado, bienestar, estilos y formas de vida, asociado a la 
imagen de modernidad. Estos hechos contribuyen a que la población llegue a sobrevalorar aquello que no es propio y se construya en el imaginario colectivo la idea positiva del país que será el lugar de destino final (2006:38-39).

En el caso de la migración cubana hacia Angola se comprobó, gracias a las entrevistas realizadas, que antes de migrar predominaba una imagen positiva del país de destino. La representación social sobre Angola desde el lugar de origen se refiere en concreto a una nación que ha cambiado mucho desde la época de la guerra y que ahora ofrece una economía en crecimiento y expansión, con oportunidades en todos los ámbitos, especialmente en el laboral, para mejorar las condiciones de vida de los inmigrantes y sus familias en el lugar de origen.

La sobrevaloración del lugar de destino contrasta con la imagen del lugar de origen, en particular en la dimensión socioeconómica, concerniente a las dificultades que encuentra la fuerza de trabajo en Cuba (en particular aquella con capacitación) a fin de mantener niveles relativos de consumo y acceder a los mecanismos de movilidad social a partir de sus bajos ingresos. En los testimonios recogidos resalta la referencia en la que se comenta que en Angola es posible hallar un trabajo que se corresponda con el nivel educacional alcanzado en Cuba y que devenga un salario superior al recibido en la Isla por la misma actividad.

Respecto a los entrevistados que establecieron su residencia en Angola durante la década de 1990, manifestaron la crítica situación del país africano en ese entonces, aún envuelto en la guerra civil. Sin embargo, su percepción del rápido crecimiento económico de la nación a comienzos del siglo XXI y las opciones de empleo que brinda a los trabajadores migrantes según su capacitación y entrenamiento, aunado a una remuneración elevada, se contrapone constantemente con su percepción acerca de la realidad cubana.

Cuando llegué a Angola en 1993 el país había salido de una etapa de guerra interna, estaba muy destruido, mucha basura en la calle, escasez de mercados, tiendas donde comprar los productos, por lo que todo o casi todo tenía que comprarse en plazas sin condiciones de higiene; existía un índice elevado de delincuencia, de mutilados de guerra en la calle exigiendo limosnas, se respiraba un clima de inseguridad enorme; pocas escuelas, en fin. Para serle sincera por algunos momentos sentí deseos de volver para Cuba, la realidad de Angola en aquellos tiempos era bien diferente de lo que es ahora (testimonio de una migrante cubana en Luanda). 
Llegué en un momento difícil del país, pero en Cuba también la cosa estaba dura. Llevaba pocos años ejerciendo como médico, estaba recién graduado, como dicen, salido del cascarón, y mi hijo acababa de nacer. Mi salario, como el de muchos, no era nada y, a ver, tampoco es que hubiera mucho para comprar. Digamos que surgió la oportunidad de ir a trabajar a Angola. Es muy difícil irte y dejar a los tuyos atrás y saber que pasará mucho tiempo para volverlos a ver, pero también tienes que pensar en darles una vida mejor. La situación en Angola estaba muy complicada en esos años, pero se vislumbraba que el país tendría una oportunidad cuando la situación política se normalizara. Es un país con muchos recursos, tiene de todo. En los últimos años ha tenido un crecimiento económico asombroso y los que estábamos ahí desde la época de la guerra estamos cosechando lo nuestro también (testimonio de un migrante cubano en Luanda).

En la construcción de la representación sobre Angola influye la cotidianidad de la realidad cubana y el peso familiar de las limitaciones de ingreso y consumo de la fuerza laboral en el ámbito nacional, contexto histórico y social, del cual los migrantes no pueden desprenderse. Pese a que Angola es un país con un IDH inferior al de Cuba y con servicios sociales no garantizados por completo en comparación con Cuba, predomina la imagen negativa en torno a la situación económica en la Isla. Expresiones como «en Cuba se sobrevive, no se vive» $\mathrm{y}$ «hay que estar inventando» (con el propósito de obtener ingresos adicionales por otras fuentes) fueron utilizadas por algunos entrevistados para describir las problemáticas sociales y económicas a las que se enfrenta la mayor parte de la fuerza laboral cubana.

Estos elementos del contexto interno fortalecen la representación generalmente positiva sobre Angola. No obstante, los entrevistados resaltaron cuestiones negativas: abundancia de enfermedades desconocidas hasta ahora en Cuba, amplia brecha de desigualdades y contrastes sociales inexistente en la Isla, violencia y corrupción.

Allá los cubanos somos muy respetados y queridos por todo lo que hemos hecho por ellos, hay muchas opciones de trabajo porque es un país que se está desarrollando. Pero la cultura es muy diferente a la nuestra, aquello es África y nada tiene que ver con el Caribe. El país no tiene un sistema sanitario eficiente, hay sobrepoblación en muchas grandes ciudades; en Luanda esto es muy visible, la gente vive ahí sin condiciones de higiene, ni salubridad, así que las enfermedades contagiosas 
están a la orden del día. El sistema vial aún es un caos, es insuficiente para la cantidad de carros, por lo que siempre hay congestión. Las desigualdades sociales son muy marcadas, hay clase media y alta y una gigantesca parte de la población muerta de hambre (testimonio de un migrante cubano en Luanda).

\section{Motivaciones y aspiraciones}

Las motivaciones centrales del proyecto migratorio se asocian con elementos laborales y económicos. El total de los entrevistados declaró que trabajar en ese país y ayudar a la familia en Cuba mediante el envío de remesas eran las razones fundamentales al migrar. La aspiración de desarrollarse profesionalmente fue el otro motivo relevante para 60 por ciento de los entrevistados. De acuerdo con los testimonios, las motivaciones económicas se relacionan con la alternativa de acceder a mayores niveles de consumo de bienes materiales en comparación con su situación previa en Cuba y satisfacer necesidades básicas personales y de sus familiares en la Isla:

Venir aquí me ha permitido acceder a mejores condiciones económicas y materiales de vida según mi trabajo, cosa que en Cuba es difícil aunque sea un buen profesional (testimonio de una migrante cubana en Luanda).

Cabe destacar que 90 por ciento de los entrevistados declaró haber cumplido estos anhelos al establecerse y trabajar en Angola.

\section{Definición de «éxito»}

En las entrevistas efectuadas se constató que la definición del «éxito», en este caso, tiene que ver con la consecución de las aspiraciones económicas y laborales que propiciaron la migración y que pueden alcanzar en Angola a pesar de las innegables dificultades sociales que enfrenta el país:

He podido desarrollar mi profesión y vivir mejor, aquí hay muchas oportunidades para los profesionales, una vez tienes trabajo enseguida puedes mejorar tus condiciones de vida y ayudar a tu familia, además de que como profesional puedes vivir bien, tener cosas que era difícil, casi que imposible, conseguir en Cuba (testimonio de un migrante cubano en Luanda). 
Conseguí con grandes esfuerzos ser una empresaria bien exitosa, tengo una empresa en Portugal de exportaciones e importaciones, en Angola soy una empresaria en la rama de la construcción y ahora entré en el área de salud con un Centro Médico especializado. Cuando mi padre murió tenía 16 años, no estudié mucho, quería ser cirujana, por eso ahora con 52 años estoy realizando el sueño de tener algo relacionado con la salud (testimonio de una migrante cubana en Luanda).

Desde que llegué pude trabajar y hacer mi dinero, ya hoy tengo mi negocio y me va bien (testimonio de un migrante cubano en Luanda).

\section{Opinión sobre el proyecto migratorio}

Es pertinente comentar que todos los entrevistados conciben el proyecto migratorio de modo positivo. Además, recomiendan a familiares y amigos la opción de trabajar fuera de Cuba. En general, le confieren un valor al proyecto migratorio como estrategia de compensación en el nivel individual y familiar para enfrentar la situación de limitación económica estructural del sistema productivo cubano. A través de esa estrategia se pueden incrementar y diversificar las fuentes de ingreso del núcleo familiar al promover su movilidad social en el contexto de origen, así como cubrir necesidades básicas y acceder a mayores niveles de consumo en el contexto de llegada.

En ese sentido, los migrantes «conciben la migración como una oportunidad beneficiosa, un anhelo positivo en el sentido económico que permite mejorar sus condiciones de vida mediante el cumplimiento de expectativas concretas vinculadas a la adquisición de ciertos bienes materiales que permitan proyectarse en un futuro mejor» (Montero, 2006:39). Sin embargo, en los criterios emitidos por los entrevistados pesa de forma negativa la añoranza por la familia y la vida en la Isla:

La verdad le digo que independientemente de dónde vivamos y el motivo por el cual salimos de Cuba seguimos amando a nuestra patria, nuestra identidad no se anula por haber adquirido otra nacionalidad, que en el fondo sólo nos ayuda en cuestiones profesionales o económicas, porque a los ojos de los demás seguiremos siendo cubanos eternamente y dicho sea de paso con mucho orgullo. No recuerdo una semana en que en mi casa no se haga una comida típicamente cubana, no se escuche una música, no bailemos hasta mambo y no se nos llenen los ojos de lágrimas al recordar Cuba. Fuera de Cuba podemos constituir familia —la mía es 
adorable—, tener tal vez mejores condiciones económicas diría yo, más bien materiales, pero no tenemos amigos de infancia, parque infantil que nos sirva de referencia para llevar a nuestros hijos, no tenemos el abrazo de un hermano, ni mamá para que nos permita llorar en su hombro y muchas cosas más que quizá no entienda (testimonio de una migrante cubana en Luanda).

\section{Regreso a Cuba}

Aunque el deseo de regresar a Cuba es una constante en 80 por ciento de los entrevistados, luego de un tiempo determinado en el exterior o a pasar la vejez, la oportunidad de establecerse en una sociedad que les garantiza niveles de vida relativamente mejores que en el país de origen y que les permite ayudar a sus familiares, es un incentivo a continuar con el proyecto migratorio. Ante los elementos negativos que deben enfrentar en el desarrollo de este proyecto, prevalece la idea de que trabajar en el extranjero y regresar a Cuba tras haber acumulado cierto capital y garantizar mejores condiciones de vida en la Isla (arreglar la vivienda o adquirir una nueva, comprar un automóvil, montar un negocio, entre otras) es una estrategia acertada.

Se debe apuntar a la reflexión que la situación social de Angola y su bajo nivel de desarrollo humano en comparación con Cuba contribuyen a percibir la migración hacia este destino como una estrategia de carácter temporal. El deseo de regresar a Cuba después de conseguir las aspiraciones económicas previas al inicio de la migración se interpreta como parte del «éxito» del proyecto migratorio.

\section{Perspectiva de las familias de los migrantes en el país de origen}

En las entrevistas a los residentes en la Isla que al menos tenían un familiar en Angola se aprecian puntos en común con los testimonios de los migrantes en las distintas dimensiones del contenido de las representaciones sociales. Esta coincidencia se debe a los factores sobre los que se basa su construcción. En las respuestas influyó de manera significativa la opinión transmitida y la experiencia vivida por su familiar en Angola. Desde la perspectiva de los entrevistados las representaciones constituyen una continuidad, no tanto un nuevo aporte a sus contenidos. 
Al profundizar en la idea anterior, sobresale que entre las familias de los migrantes también predominan las representaciones positivas sobre el país de destino y el proyecto migratorio. La imagen positiva de Angola se relaciona con el rápido crecimiento económico del país, las oportunidades laborales que ofrece (en especial para los profesionales) y los elevados salarios en comparación con el contexto cubano. Por otra parte, la representación positiva del proyecto migratorio se asocia a la realización de las aspiraciones de los migrantes, ya analizadas, y que entrañan beneficios socioeconómicos al acceder a mayores niveles de ingreso. Estos elementos influyeron para que 90 por ciento de los entrevistados recomendara a otras personas la opción de ir a trabajar a Angola.

No obstante, la totalidad de los familiares entrevistados en Cuba indicó que la existencia de cuestiones negativas vinculadas con el nivel de desarrollo humano de Angola afecta el proyecto migratorio. La problemática sanitaria y la presencia de enfermedades desconocidas en Cuba o erradicadas en etapas anteriores fue el elemento más destacado, señalado por 70 por ciento de los entrevistados. Le siguieron la situación de violencia e inseguridad en algunas áreas urbanas y la gran brecha de desigualdad social que enfrenta el país:

Mi primo vive allá desde el 2003, al principio pasó mucho trabajo porque estaba lejos de su familia y por la inestabilidad laboral. Dice que es un país con cosas buenas y malas, pagan buenos salarios, las cosas son baratas pero hay que evitar salir de noche, hay mucha desigualdad en el desarrollo del país y zonas de peligro (testimonio de un familiar de migrante en La Habana).

Desde que mi hermano está allá ha podido ahorrar dinero y vivir bien, también me ha ayudado a mí. Pero aquello no es fácil, dice que hay muchas enfermedades a las que nosotros no estamos acostumbrados, hay que cuidarse y más cuando uno va con niños pequeños (testimonio de un familiar de migrante en La Habana).

En cuanto a las motivaciones, es recurrente la aspiración de que su familiar acceda a un trabajo que permita satisfacer sus necesidades básicas de consumo y las de su familia en el país de origen:

Mi hijo se fue hace casi diez años, después se llevó a mi nuera y los niños. Están muy bien allá. Los dos trabajan y ganan bien. Han ido de vacaciones a varios lugares y les están dando una buena vida a los niños. A nosotros nos han ayudado 
cantidad, nos mandan dinerito para los gastos aquí y cosas que aquí son caras. A mí me invitaron de vacaciones para que estuviera con los niños (testimonio de un familiar de migrante en La Habana).

En el país de origen la familia reproduce y transmite la definición de «éxito» asociada al proyecto migratorio y que se articula a partir de los bienes materiales de su familiar en el país de destino, así como la relevancia de los envíos de remesas financieras y materiales para la economía familiar: «Las representaciones sociales y los imaginarios que se han construido en el país de origen corresponden al éxito y bienestar que la migración puede generar y que es palpable ante la materialización de los bienes materiales como casas, terrenos, vehículos» (Montero, 2006:37).

Mi hija solo lleva allá cuatro años y ha conocido todo Angola, y además fue a Sudáfrica de vacaciones. Vive sola en una casita con todo y tiene su carro. Todos los meses me manda dinero y siempre me está diciendo que lo que necesite se lo pida, que ella me lo manda. Ya me arregló el baño y la cocina, ahora quiere ver si podemos vender esta casa para comprar otra mejor en un barrio más céntrico (testimonio de un familiar de migrante en La Habana).

Además, la definición de "éxito», concerniente a la realización de las aspiraciones, se vislumbra en el discurso oral con las frases «está bien» o «le va bien». Se identifica en una parte de las entrevistas de los familiares de migrantes cubanos en Angola y se refiere a que la situación de sus familiares es estable, que disponen de un trabajo con el que han podido adquirir bienes materiales y propiedades, algo muy difícil de realizar en Cuba a causa de los bajos niveles de ingreso.

\section{Proceso de construcción de las representaciones sociales}

Varios factores intervienen en la construcción de las representaciones sociales de la migración hacia Angola. Uno de los más importantes son las experiencias de los migrantes transmitidas a familias y amigos en la sociedad de origen a través de las cadenas sociales porque incide de forma directa. Otros elementos son las informaciones que circulan en las redes sociales y en los medios de 
comunicación nacionales que dan seguimiento al crecimiento económico angolano, a la vez que denuncian y analizan la grave situación social y humanitaria que contextualiza al continente africano en general.

Previamente se había destacado la trascendencia de la información transmitida por los migrantes gracias a las cadenas sociales creadas con cada acto migratorio. En ellas, las llamadas telefónicas, los mensajes por correo y las visitas a Cuba funcionan como canales directos de comunicación y de transmisión de la información acerca del país de destino, las ventajas y desventajas del proyecto migratorio o sus costos, lo que contribuye a tomar la decisión de emigrar o no, aunado al conocimiento acumulado sobre las potencialidades del lugar de destino. Es decir, las cadenas son de vital importancia por su desempeño en la construcción de las representaciones sociales y en la toma de la decisión migratoria. Al respecto, 60 por ciento de los migrantes entrevistados declaró que los criterios de amigos que ya vivían en ese lugar o de familiares ya establecidos influyeron en su decisión; en algunos casos, saber que contaban con el apoyo de esas personas hizo más seguro el proyecto migratorio:

Mi hermano vive allá hace algunos años, es ingeniero y trabaja en la construcción, le va bien y siempre me dijo que tenía oportunidades, que fuera para allá con él. En ese momento estaba recién graduado, así que esperé a terminar el servicio social para irme (testimonio de un migrante cubano en Luanda).

Un amigo de mi hijo le consiguió trabajo en una empresa como contador, él le aseguró que allá tenía oportunidades y que lo ayudaría. Mi hijo legalizó sus papeles y se fue por contrato de trabajo. A los dos años de estar allá y de ver que la cosa era segura y que marchaba bien inició los trámites para llevarse a mi nuera y los niños. Todo eso es muy caro, se necesitaron muchos papeles y dinero, pero él ya estaba bien y podía pagarlo todo. Ahora él quiere ayudar a mi sobrina, ella está estudiando en la universidad y quiere conseguirle algo para que cuando termine pueda ir a trabajar allá (testimonio de un familiar de migrante en La Habana).

Más allá de las condiciones histórico-estructurales en que surge y se desarrolla el proyecto migratorio, las cadenas migratorias intervienen en la decisión de emprender el viaje, no sólo por su capacidad de circular información que haga factible construir las representaciones en torno al lugar de destino y los costosbeneficios de la acción migratoria, sino por su capacidad de proporcionar los medios necesarios para efectuar el proyecto. En palabras de Montero, 
las redes de familiares y de amigos, tanto en el país de origen como en el de destino, agilizan y reproducen el proceso migratorio al intercambiar información para construir representaciones: crear el imaginario del país de destino como el lugar idóneo para cumplir sus aspiraciones personales y las de sus familiares, incentivar e invitar a realizar el viaje, préstamo de dinero para pagar el mismo, facilitar el acceso a la vivienda, al trabajo y la inserción misma en el país de destino, es decir, llegan a crear una especie de institución de soporte y solidaridad para los nuevos inmigrantes (2006:37).

En un círculo estrechamente interrelacionado, las cadenas migratorias propician los canales para el intercambio de información en la elaboración de las representaciones sociales del país de destino (en este caso positivas en su mayoría) y los beneficios que puede brindar el proyecto migratorio, incluso en ocasiones lo apoyan. Cada nuevo hecho migratorio refuerza los elementos que sustentan la representación sobre el país de destino, al mismo tiempo que crea un nuevo eslabón en la cadena de circulación de datos relativos a la migración.

\section{Conclusiones}

Aunque Angola es un destino de corta tradición desde la perspectiva histórica y los cubanos que han emigrado hacia este país no constituyen un número significativo en comparación con el total de emigrados cubanos en el mundo, ni con los grupos establecidos en otros países receptores, las representaciones sociales provenientes del país de origen acerca de Angola y el proceso migratorio y sus contenidos asociados al "éxito», intervienen en la decisión individual de emprender el viaje y contribuyen a la reproducción de la migración.

La relación se determina a partir de varios elementos. Uno es la imagen positiva que se percibe de Angola como lugar en el que se pueden alcanzar las metas propuestas con el proyecto migratorio, pese a que es un país con un desarrollo humano inferior al de Cuba. Es pertinente destacar la imagen de «éxito» formada alrededor de los cubanos que laboran en ese país (en su mayoría se trata de profesionales empleados en los sectores de la salud y la educación) y la presencia de cadenas sociales activas capaces de facilitar la circulación de información, las cuales son fundamentales en la construcción de las representaciones sobre esta acción social; asimismo, apoyan el proyecto migratorio mediante sus múltiples nexos. 
Las características históricas de los contextos implicados en el proceso migratorio de cubanos hacia Angola se manifiestan en el contenido de las representaciones sociales. El individuo no actúa de modo aislado, ni las representaciones sociales de la migración se construyen de manera separada. Los contextos social, económico y político en los que interaccionan los individuos, en los ámbitos familiar, local (nacional) y global, determinan sus trayectorias y las múltiples formas en que son representadas socialmente.

Por lo general, la representación positiva de Angola, las oportunidades laborales que ofrece y las ventajas económicas relativas a mayor remuneración salarial, nivel de consumo y movilidad social ascendente (en especial para los profesionales) en comparación con la situación en el país de origen, es un elemento significativo en la elección de este destino y en la decisión de iniciar el proyecto migratorio como estrategia individual y familiar.

Complementariamente, las representaciones tributan al proceso migratorio puesto que influyen, entre otros factores, en su reproducción y continuidad en el tiempo, una vez que participan en la decisión de iniciar el viaje y permiten la validación de la estrategia migratoria como solución a una situación socioeconómica concreta (individual, familiar o local).

\section{Referencias}

Amaro Cano, Leonor (2013), «Angola y Cuba. Familias limitadas por la política y la guerra», Catauro. Revista Cubana de Antropología, 27(14).

Agencia Angola Press (ANGOP) (2014), "Más de 1400 extranjeros expulsados de Angola por estancia ilegal la última semana», en http://www.portalangop.co.ao

Arboleya Cerbera, Jesús (2013), Cuba y los cubanoamericanos. El fenómeno migratorio cubano, La Habana, Cuba, Fondo Editorial Casa de las Américas.

Araya Umaña, Sandra (2002), Las representaciones sociales: Ejes teóricos para su discusión (Cuaderno de Ciencias Sociales 127), San José, Costa Rica, Facultad Latinoamericana de Ciencias Sociales (Flacso), en http://unpan1.un.org/intradoc/groups/ public/documents/ICAP/UNPAN027076.pdf

Baldé, Assanatou (8 de junio de 2012), «África, żnuevo El Dorado de los migrantes europeos?», Diario Granm, 157(16).

Castles, Stephen (2013), «Migración, trabajo y derechos precarios: perspectivas histórica y actual», Migración y Desarrollo, 11(20). 
Colectivo de Autores (2012), Evaluación del proceso migratorio externo y la emigración cubana en el periodo 2010-2015. Principales tendencias e implicaciones para Cuba (informe inédito), Cuba, Centro de Estudios de Migraciones Internacionales (CEMI).

(2014), Balance del proceso migratorio externo cubano tras un año de la aplicación de la nueva Ley de Migración y su Reglamento (informe inédito), Cuba, Centro de Estudios de Migraciones Internacionales (CEMI).

Espina Prieto, Mayra Paula (2009), «Pobreza, desigualdad y desarrollo: el rol del Estado en la experiencia de Cuba", en Cimadamore, Alberto, Dean, Hartley, Siqueira, Jorge (eds.), La pobreza del Estado. Reconsideración del rol del Estado en la lucha contra la pobreza global, Buenos Aires, Argentina, Clacso, pp. 177-191.

(2015), «La política social en cuba: nueva reforma económica», en Jorge Hernández Martínez (comp.), Antología del pensamiento crítico cubano contemporáneo, Buenos Aires, Argentina, Clacso, pp. 263-273.

Fresneda Camacho, Edel José (2014), «Migrantes en el socialismo: el desarrollo cubano a debate», Problemas del Desarrollo, 45(176), en http://www.redalyc.org/ pdf/118/Resumenes/Resumen_11829716006__.pdf

Fresneda Camacho, Edel José y Delgado Wise, Raúl (2013), «Migración y desarrollo en Cuba: socialismo, subdesarrollo productivo y globalización neoliberal», Migración y Desarrollo, 11(20).

Gaete Quezada, Ricardo y Rodríguez Sumaza, Carmen (2010), «Una aproximación al análisis de las cadenas migratorias en España a partir de la Encuesta Nacional de Inmigrantes», Revista de Ciencia Politica, 30(3), pp. 697-721.

George, Edward (2005), The Cuban Intervention in Angola, 1965-1991. From Che Guevara to Cuito Cuanavale, London, Frank Cass.

González López, David (2011), «Solidaridad, compromiso y deber de retribución: medio siglo de interacción de Cuba con África perfilando el espíritu de la cooperación Sur-Sur», en Kabunda Badi, Mbuyi (coord.), África y la cooperación con el Sur desde el Sur, Madrid, Observatorio sobre la realidad social del África Subsahariana.

González López, David y Walterio Lord Garnes (2014), Legado africano. Herencias, antillanidad, panafricanismo y reanudaciones, Santiago de Cuba, Editorial del Caribe/ Editorial Oriente.

International Conference on Population and Development (ICPD) (2012), Angola. Country Implementation Profile, en http://www.unfpa.org/ICPD_AO

Instituto Nacional de Estadística (INE) (2014), Resultados preliminares do recenseamento geral da população e habitação de Angola, en https://andine.ine.gov.ao/nada4/ index.php/catalog/14 
Jodelet, Denise (1984), "La representación social: fenómeno, concepto y teoría», en Moscovici, Serge (comp.), Psicología Social II, Barcelona, Paidós, 469-494, en https://sociopsicologia.files.wordpress.com/2010/05/rsociales-djodelet.pdf.

Jover, Estefanía, Lopes Pinto, Anthony y Marchand, Alexandra (2012), Angola. Private Sector Country Profile, en https://www.afdb.org/fileadmin/uploads/afdb/ Documents/Evaluation-Reports-_Shared-With-OPEV_/Angola\%20-\%20Private \%20Sector\%20Country\%20Profile\%20-\%20Version\%20Portugaise.pdf.

López-Calleja, Cristina (2008), Las migraciones internacionales potenciales y efectivas en Cuba, en www.alapop.org/2009/images/DOCSFINAIS_PDF/ALAP_2008_FINAL_ 95.pdf

Martín Fernández, Consuelo, Antonio Aja Díaz, Ángela Casaña Mata y Magali Martín Quijano (2007), «La emigración de Cuba desde fines del siglo XX y principios del XXI: lecturas y reflexiones mirando a la ciudad de La Habana», en Anuario Digital CEMI 2007-2008. Migraciones Internacionales y Emigración Cubana, en http://www.uh.cu/centros/cemi/index.htm

Martín Romero, José Luis (2012), «Integración social y trabajo en Cuba: retos y oportunidades de un modelo en proceso de cambio", Novedades en población, 8(15), pp. $34-44$.

Montero, Gabriela (2006), "Las representaciones sociales de los emigrantes ecuatorianos en España sobre el proceso migratorio», Revista Alternativas. Cuadernos de Trabajo Social, 14, en http://rua.ua.es/dspace/bitstream/10045/6504/1/ALT_14_03. pdf

Mora, Martín (2002), "La teoría de las representaciones sociales de Serge Moscovici», Athenea Digital (2), en http://blues.uab.es/athenea/num2/Mora.pdf

Moscovici, Serge (1979), El psicoanálisis, su imagen y su público, Buenos Aries, Argentina, Huemul.

Oficina de Información Diplomática del Ministerio de Asuntos Exteriores y de Cooperación (2012), Ficha país Angola. República de Angola, en http://www.exteriores. gob.es/Documents/FichasPais/ANGOLA_FICHA\%20PAIS.pdf

Organización Internacional para los Migrantes (OIM) (2014), Informe sobre las migraciones en el mundo 2013. El bienestar de los migrantes y el desarrollo, en http://publications.iom.int/books/informe-sobre-las-migraciones-en-el-mundo-2013-1

Organización Mundial del Comercio (OMC) (1995), Acuerdo General Sobre Comercio de Servicios, en https://www.wto.org/spanish/tratop_s/serv_s/gatsqa_s.htm 
Oficina Nacional de Estadística e Información (ONEI) (2014a), Anuario Demográfico de Cuba 2013, en http://www.onei.cu/publicaciones/cepde/anuario_2013/5_flujo. pdf

(2014b), Anuario Estadístico de Cuba 2013, en http://www.onei.cu/aec2013/ esp/20080618_tabla_cuadro.htm

Organización de las Naciones Unidas (ONU) (2002), Angola: The Post-War Challenges, en http://citeseerx.ist.psu.edu/viewdoc/summary?.doi=10.1.1.134.3908

Pedone, Claudia (2002), "Las representaciones sociales en torno a la inmigración ecuatoriana a España», Revista de Flacso-Ecuador ICONOS, 14, en www.flacso.org.ec/ docs/i14_pedone.pdf

(2010), «Cadenas y redes migratorias: propuesta metodológica para el análisis diacrónico-temporal de los procesos migratorios», Empiria. Revista de Metodología de Ciencias Sociales (19), pp. 101-132, en http://www.redalyc.org/pdf/2971 /297126345004.pdf

Pérez García, Yulianela (2013), «La migración hacia África en la actualidad: el caso de los cubanos residentes en Angola», Novedades en población, 18, pp. 46-45, en http:// www.cedem.uh.cu/revista

(2015), Migración y trabajo entre las regiones del Sur desde la perspectiva global. Un análisis del flujo de cubanos hacia Angola, Buenos Aires, Clacso, en http://www. clacso.org.ar/libreria-latinoamericana/libro_detalle.php?orden=\&id_libro= 1061\&pageNum_rs_libros $=0$ \& trotalRows_rs_libros $=1027$

Pérez Villanueva, Omar Everleny (2009), «La estrategia económica cubana: medio siglo de socialismo», Cahiers des Amériques latines (57-58), en http://cal.revues. org/1206

Programa de las Naciones Unidas para el Desarrollo (PNUD) (2014), Informe sobre desarrollo humano 2014. Sostener el progreso humano: reducir vulnerabilidades y construir resilencia, en http://www.undp.org/content/undp/es/home/librarypage/hdr/ 2014-human-development-report.html

Silva León, Arnaldo (2003), Breve historia de la Revolución Cubana 1959-2000, La Habana, Cuba, Editorial de Ciencias Sociales.

Sorolla Fernández, Ileana (2013), "Apuntes de un cuaderno de bitácora: continuidades y cambios en el patrón migratorio externo cubano (2000-2010)», en Cárdenas Menéndez, Eliana y Sierra Sosa, Ligia (coords.), Encuentros y divergencias: dinámicas migratorias desde la frontera sur, México, Universidad de Quintana Roo.

Fondo de las Naciones Unidas para la Infancia (Unicef) (2015), Angola. Estadísticas, en http://www.unicef.org/spanish/infobycountry/angola_statistics.html. 
Vidal Alejandro, Pavel, Pérez Villanueva, Omar y González Corzo, Mario (2010), "Labor Force and Economic Changes in Cuba", Delaware Review of Latin American Studies, 12(1). 